\title{
Terminação de novilhos mestiços leiteiros sob pastejo, no período das águas, recebendo suplementação com soja
}

\author{
Mário Fonseca Paulino ${ }^{1}$, Eduardo Henrique Bevitori Kling de Moraes ${ }^{2}$, Joanis Tilemahos \\ Zervoudakis $^{3}$, Emerson Alexandrino ${ }^{4}$, Darcilene Maria de Figueiredo ${ }^{2}$

\footnotetext{
1 Universidade Federal de Viçosa, Viçosa - MG, 36570-000.

2 Pós-graduação - UFV, Viçosa - MG.

3 Universidade Federal do Mato Grosso, Cuiabá - MT.

4 Universidade Federal de Rondônia, Rolim de Moura - RO.
}

RESUMO - Objetivou-se avaliar o efeito da utilização da soja em diferentes formas físicas em suplementos múltiplos para terminação de bovinos em pastejo sobre o ganho médio diário (GMD), o ganho de peso total (GT), o rendimento de carcaça (RC), o pH e a amônia ruminal. Os tratamentos consistiram da suplementação com grão de soja moído (GSM), grão de soja inteiro (GSI) e farelo de soja + milho moído (FSM), fornecidos três vezes/semana, e do fornecimento de mistura mineral (controle). Para avaliar o desempenho, utilizaram-se 16 novilhos mestiços Holandês-Zebu, não-castrados, com 19 meses de idade e peso médio inicial de $316 \mathrm{~kg}$. Os valores de $\mathrm{pH}$ e as concentrações de amônia ruminal foram obtidos utilizando-se quatro novilhos mestiços Holandês-Zebu fistulados no rúmen. Os suplementos GSM, FSM e GSI proporcionaram ganhos adicionais de 143,0; 142,0 e 135,0 g/animal/dia, respectivamente, ocasionando redução no período de terminação dos bovinos em pastejo. O rendimento de carcaça e os valores de $\mathrm{pH}$ (média de 6,51) não foram influenciados pelos tratamentos. A concentração de amônia ruminal dos bovinos do tratamento sem suplementação foi inferior à observada nos animais sob suplementação.

Palavras-chave: Brachiaria decumbens, desempenho, grão de soja, proteína, suplementação

\section{Effects of supplementing soybean to crossbreed steers finished at pasture during the wet season}

\begin{abstract}
The objective of this trial was to evaluate the effects of different physical forms of soybean on average daily weight gain (ADWG), final body weight (FBW), carcass yield $(\mathrm{CY})$, ruminal $\mathrm{pH}$, and ruminal ammonia concentration on crossbred steers fineshed at pasture. Animals were fed three times per week a supplement containing a mineral mix and one of the following protein sources: ground whole soybean (GWS), whole soybean (WSB) or soybean meal and ground corn (SMGC); steers on control treatment received only a mineral mix. Sixteen crossbreed steers averaging 19 months of age and initial body weight of $316 \mathrm{~kg}$ were used in this study. Four steers fitted with ruminal cannulas were used to measure ruminal $\mathrm{pH}$ and concentration of ruminal ammonia. Supplementing steers with GWS, SMGC, or WSB yielded additional weight gains of 143.0, 142.0, and $135.0 \mathrm{~g} / \mathrm{animal} / \mathrm{day}$, respectively, when compared to control animals suggesting a reduced time to finishing protein-supplemented steers at pasture. No significant differences in $\mathrm{CY}$ were observed across treatments in this trial. Ruminal $\mathrm{pH}$ also did not differ averaging 6.51 among supplements. Conversely, concentration of ruminal ammonia was lower on animals receiving only mineral mix than on those fed protein supplements.
\end{abstract}

Key Words: performance, protein, signal grass, soybean grain, supplementation

\section{Introdução}

As flutuações na produção e na qualidade de forragens, somadas à necessidade de intensificação do setor pecuário, tornam a suplementação a pasto uma estratégia viável, que visa incrementar as eficiências reprodutiva e produtiva, permitindo maior giro de capital e possibilidade de melhorar a rentabilidade da atividade.

No período chuvoso, as pastagens tropicais têm possibilitado desempenho inferior ao potencial genético dos animais. Segundo Poppi\& McLennan(1995), para o expressivo aumento anual na taxa de crescimento animal (aproximadamente $50 \mathrm{~kg} /$ animal) em pastagens tropicais, o ganho de peso na estação chuvosa deveria ser aumentado em torno de $300 \mathrm{~g} / \mathrm{dia}$.

O uso da suplementação alimentar no período das águas é uma opção para o suprimento de nutrientes limitantes (Paulino et al., 2001), pois favorece o aumento da eficiência de utilização das pastagens (Poppi \& McLennan, 1995), proporcionando redução considerável nos ciclos de produção de bovinos em regime de pastejo.

Pesquisadores têm observado que o fornecimento de suplementos em diferentes freqüências semanais, quando 
comparado ao fornecimento diário, propicia desempenhos satisfatórios (Farmer et al., 2001; Moraes et al., 2005), o que justifica sua recomendação em sistemas em que se almeja a obtenção de maiores ganhos de peso vivo em bovinos em pastejo no período das águas, com oportunidade de redução dos gastos com mão-de-obra e equipamentos utilizados na suplementação.

Um dos alimentos utilizados em suplementação é a soja e seus derivados, por conter proteína com composição de aminoácidos razoavelmente balanceada. A soja é mais utilizada na alimentação de bovinos na forma de farelo. Entretanto, tem-se observado maior utilização do grão como fonte alternativa de suplementação protéica. Além disso, em razão do conteúdo de gordura no grão, o uso do grão de soja como componente de dietas para bovinos difundiu rapidamente (Tice et al., 1993). A substituição do farelo de soja pelo grão pode promover ganho semelhante (Sampaio et al., 1995), oferecendo vantagem econômica em relação aos suplementos formulados com o farelo (Mader, 1988, citado por Albro et al., 1993), uma vez que possui menor preço de mercado. Todavia, de acordo com Faldet \& Satter (1991), a proteína encontrada no grão de soja é facilmente degradada pelos microrganismos do rúmen e pode ser facilmente eliminada, devendo ser considerada ainda a liberação de quantidades elevadas de produtos nitrogenados no rúmen. Adicionalmente, segundo Teixeira (1997), o grão deve ser moído ou triturado antes da utilização na alimentação animal.

Na literatura, verificam-se poucos trabalhos envolvendo a utilização do grão de soja inteiro ou moído na formulação de suplementos múltiplos para bovinos em regime de pastejo no período das águas. A possibilidade de uso do grão de soja integral cria um canal de negociação direto produtorprodutor, gerando maior flexibilidade para os ajustes econômicos.

Entretanto, estima-se que $65 \%$ do rebanho bovino do estado de Minas Gerais é explorado com dupla finalidade, observando-se que os machos provenientes de rebanhos leiteiros são utilizados para recria e engorda como gado de corte (Pires et al., 1995).

Nesse contexto, avaliou-se o desempenho de bovinos de origem leiteira terminados em pastejo, submetidos, três vezes por semana, à suplementação com grão de soja inteiro, grão de soja moído ou farelo de soja.

\section{Material e Métodos}

O experimento foi realizado na Central de Experimentação, Pesquisa e Extensão do Triângulo-CEPET/UFV, loca- lizada em Capinópolis-MG, durante o período das águas, entre os meses de novembro de 2001 e fevereiro de 2002.

A área experimental foi constituída de quatro piquetes de Brachiaria decumbens Stapf de 1,5 ha, providos de bebedouro e comedouro coberto medindo $2,0 \mathrm{~m}$ de comprimento.

Na Tabela 1 constam a composição dos suplementos e seus respectivos teores de nutrientes digestíveis totais (NDT) e proteína degradável no rúmen (PDR). O grão de soja foi triturado em moinho com peneira de malha de $5,0 \mathrm{~mm}$.

Quantidades equivalentes a $500 \mathrm{~g} / \mathrm{animal} / \mathrm{dia}$ foram fornecidas aos animais às segundas, quartas e sextasfeiras, às $10 \mathrm{~h}$, com o objetivo de atender aproximadamente $20 \%$ das exigências de proteína preconizadas pelo NRC (2001). Simultaneamente, foi avaliado o tratamento controle (mistura mineral), no intuito de analisar o desempenho dos animais não submetidos à suplementação.

Para a avaliação do desempenho, foram utilizados 16 novilhos mestiços Holandês-Zebu, não-castrados, com 19 meses de idade e peso médio inicial de $316 \mathrm{~kg}$. Os animais, após jejum de sólidos e líquidos durante 18 horas, foram pesados no início do experimento e a cada 28 dias e, em seguida, distribuídos aleatoriamente entre os tratamentos.

Os animais permaneceram nos piquetes por sete dias e, depois desse período, foram rotacionados, visando minimizar a influência de possíveis diferenças na disponibilidade de MS entre os piquetes, mantendo-se o mesmo suplemento alimentar.

No primeiro dia de cada período experimental, coletaram-se amostras da forragem consumida pelos animais, via simulação manual de pastejo, segundo Johnson (1978), para determinação da disponibilidade total de matéria seca/ha, por meio do corte, a $10 \mathrm{~cm}$ do solo, de cinco áreas delimitadas por um quadrado metálico de $0,5 \times 0,5 \mathrm{~m}$, em pontos escolhidos aleatoriamente em cada piquete experimental (McMeniman, 1997).

As amostras foram pré-secas em estufa ventilada, por 72 horas, processadas em moinho com peneira com malha de 1,0 $\mathrm{mm}$ e acondicionadas em potes de plástico.

Foram determinados os teores de MS, nitrogênio total (N), EE, cinzas e FDN. Com exceção das análises de FDN, feitas segundo Van Soest (1991), as demais foram efetuadas conforme recomendações de Silva \& Queiroz (2002). Os carboidratos totais (CT) foram estimados pela equação: $100-(\% \mathrm{~PB}+\% \mathrm{EE}+\%$ Cinzas) (Sniffen et al., 1992) e os $\mathrm{CNF}$, pela diferença entre CT e FDN.

Para avaliação dos parâmetros ruminais, utilizaram-se quatro novilhos Holandês-Zebu fistulados no rúmen. As leituras de $\mathrm{pH}$ foram realizadas logo após a coleta do líquido ruminal por meio de peagâmetro digital. Os teores de amônia foram determinados em $50 \mathrm{~mL}$ de líquido ruminal, adiciona- 
Tabela 1 - Composição dos suplementos (\%), na matéria natural, e teores de NDT e PDR nos diferentes tratamentos

Table 1 - Ingredient composition of supplements (as-fed basis), contents of TDN and RDP of different treatments

\begin{tabular}{|c|c|c|c|c|}
\hline \multirow[b]{2}{*}{ Item } & \multicolumn{4}{|c|}{$\begin{array}{c}\text { Tratamento } \\
\text { Treatment }\end{array}$} \\
\hline & $\begin{array}{c}\mathrm{MM}^{1} \\
M M\end{array}$ & $\begin{array}{c}\mathrm{GSM}^{2} \\
G W S\end{array}$ & $\begin{array}{l}\mathrm{GSI}^{3} \\
W S B\end{array}$ & $\begin{array}{l}\mathrm{FSM}^{4} \\
S M G C\end{array}$ \\
\hline $\begin{array}{l}\text { Mistura mineral }(\mathrm{MM})^{5} \\
\text { Mineral mix }\end{array}$ & 100,00 & 9,09 & 9,09 & 9,09 \\
\hline $\begin{array}{l}\text { Grão de soja moído } \\
\text { Ground whole soybean }\end{array}$ & - & 90,01 & - & - \\
\hline $\begin{array}{l}\text { Grão de soja inteiro } \\
\text { Whole soybean }\end{array}$ & - & - & 90,01 & - \\
\hline $\begin{array}{l}\text { Farelo de soja } \\
\text { Soybean meal }\end{array}$ & - & - & & 65,46 \\
\hline $\begin{array}{l}\text { Milho moído } \\
\text { Ground corn }\end{array}$ & - & - & & 25,45 \\
\hline $\begin{array}{l}\text { Composição } \\
\text { Composition }\end{array}$ & & & & \\
\hline $\begin{array}{l}\text { NDT }(T D N)^{6} \\
\text { PDR }(R D P)^{6,7}\end{array}$ & $\begin{array}{l}- \\
-\end{array}$ & $\begin{array}{l}82,06 \\
59,62\end{array}$ & $\begin{array}{l}82,06 \\
59,62\end{array}$ & $\begin{array}{l}74,85 \\
60,11\end{array}$ \\
\hline
\end{tabular}

${ }^{1}$ Mistura mineral; ${ }^{2}$ Grão de soja moído; ${ }^{3}$ Grão de soja inteiro; ${ }^{4}$ Farelo de soja + milho moído; ${ }^{5}$ Composição percentual: fosfato bicálcico, 50,00; cloreto de sódio, 44,15; sulfato de zinco, 1,50; sulfato de cobre, 0,75; sulfato de cobalto, 0,05 ; iodato de potássio, 0,05 e sulfato de magnésio: 0,5; ${ }^{6}$ Estimado segundo Valadares Filho et al. (2002); $7 \%$ MS.

${ }^{1}$ Mineral mix; ${ }^{2}$ Ground whole soybean; ${ }^{3}$ Whole soybean; ${ }^{4}$ Soybean meal + ground corn; ${ }^{5}$ Percentage composition: dicalcium phosfate, 50.00; sodium chloride, 44.15; zinc sulfate, 1.50; copper sulfate, 0.75 ; cobalt sulfate 0.05 ; potassium iodate, 0.05 ; and magnesium sulfate; ${ }^{6}$ Estimated according to Valadares Filho et al. (2002): 7 \% DM.

dos de $1,0 \mathrm{~mL}$ de $\mathrm{H}_{2} \mathrm{SO}_{4}(1: 1)$ e congelados a $-20^{\circ} \mathrm{C}$. As concentrações do $\mathrm{N}$ amoniacal foram obtidas após destilação com KOH $2 \mathrm{~N}$, segundo técnica descrita por Fenner (1965), adaptada por Vieira (1980).

Foram adotados o delineamento inteiramente casualizado, para avaliar o desempenho produtivo dos animais, e o delineamento quadrado latino, para determinação do $\mathrm{pH}$ e das concentrações de amônia ruminal. Utilizaram-se o Sistema de Análises Estatísticas e Genéticas - SAEG (Universidade Federal de Viçosa, 2000) para análise dos resultados e o teste de Student Newman-Keuls (SNK), a 5\% de probabilidade, para comparação das médias observadas.

\section{Resultados e Discussão}

O consumo de MS por animais em pastejo está relacionado à disponibilidade e qualidade da forragem. Quando a disponibilidade de forragem se encontra abaixo de $2.000 \mathrm{~kg}$ de MS/ha, ocorre redução na ingestão de MS, em decorrência da diminuição do tamanho dos bocados e do aumento no tempo de pastejo (Minson, 1990). A disponibilidade média de matéria seca das pastagens durante o período experimental foi de $4.000 \mathrm{~kg} / \mathrm{ha}$, o que propiciou condições para que o animais exercessem seu pastejo seletivo.
A composição bromatológica das amostras de forragem e dos suplementos encontra-se na Tabela 2.

Como resultado da boa qualidade da forragem disponível aos animais, observou-se bom desempenho dos animais não submetidos à suplementação (Tabela 3). Segundo Nolan et al. (1976), aminoácidos podem ser incorporados diretamente à proteína microbiana. Desse modo, a resposta à suplementação com proteína degradável (suplementos GSM, GSI e FSM) pode ser resultante de um efeito positivo de aminoácidos préformados sobre o crescimento microbiano. Embora não tenham sido encontradas diferenças estatísticas $(\mathrm{P}>0,05)$, constatou-se superioridade numérica no GMD dos bovinos sob suplementação (em torno de 16\%) em comparação aos do tratamento controle(Tabela3). Nolan \& Leng (1972) sugeriram que a reciclagem de amônia absorvida pelo rúmen pode suportar fermentações entre tempos de suplementação.

Os suplementos GSM, FSM e GSI proporcionaram, respectivamente, ganhos adicionais de 143,142 e $135 \mathrm{~g} / \mathrm{animal} /$ dia, que, na pecuária de ciclo curto, são de grande relevância, tendo-se em vista fatores como: maior produção por área, menor tempo de ocupação das pastagens e rapidez no acabamento dos animais e, conseqüentemente, no giro de capital.

Avaliando dois suplementos, um composto de grão de soja inteiro e outro de farelo de soja, Paulino et al. (2002) não encontraram diferenças no ganho de peso dos animais na fase de terminação. Os autores encontraram, no entanto, rendimento médio de carcaça de 52,96\%, que é ligeiramente superior à média de 49,93\% observada neste estudo.

A análise do $\mathrm{pH}$ ruminal não indicou efeitos significativos $(\mathrm{P}>0,05)$ dos tratamentos sobre os suplementos, sendo encontrados valores de 6,$58 ; 6,37 ; 6,55$ e 6,53 , respectivamente para os tratamentos MM, GSM, GSI e FSM (Tabela 4). A eficiência da síntese microbiana pode reduzir significamente com valores de $\mathrm{pH}$ abaixo de 6,00. Entretanto, os valores observados foram superiores a este referencial, não sendo limitantes à adequada atividade dos microrganismos celulolíticos (Hoover, 1986).

Na análise da concentração de amônia ruminal, observou-se efeito $(\mathrm{P}<0,05)$ entre suplementos; o tratamento controle apresentou valor menor que os demais, que não diferiram $(\mathrm{P}>0,05)$ entre si (Tabela 4). Em todos os tratamentos, as concentrações de amônia ruminal se mantiveram em níveis acima de $5 \mathrm{mg} / \mathrm{dL}$ (Satter \& Slyter, 1974), considerados mínimos para adequada fermentação ruminal da fibra. Segundo Leng (1990), para adequada fermentação em condições tropicais, a concentração de amônia no rúmen deve estar acima de $10 \mathrm{mg} / \mathrm{dL}$ de líquido ruminal. Portanto, as concentrações foram inferiores aos valores sugeridos apenas no tratamento controle, o que pode ter prejudicado o consumo voluntário. 
Tabela 2 - Teores médios de MS (MS\%), MO, PB, EE, cinzas, CT, FDN e CNF da $B$. decumbens e dos suplementos Table 2 - Average contents of DM (DM\%), OM, CP, EE, ash, TC, NDF and NFC of B. decumbens and supplements

\begin{tabular}{|c|c|c|c|c|c|}
\hline \multirow[b]{2}{*}{ Item } & \multicolumn{5}{|c|}{$\begin{array}{c}\text { Tratamento } \\
\text { Treatment }\end{array}$} \\
\hline & $\mathrm{MM}^{1}(M M)$ & $\mathrm{GSM}^{2}(G W S)$ & $\mathrm{GSI}^{3}(W S B)$ & $\mathrm{FSM}^{4}(S M G C)$ & B.decumbens 5 \\
\hline $\operatorname{MS}(\%)(D M)$ & 98,70 & 81,90 & 81,90 & 81,00 & 33,56 \\
\hline $\mathrm{MO}^{6}(\mathrm{OM})$ & - & 95,00 & 95,00 & 95,45 & 92,77 \\
\hline $\mathrm{PB}^{6}(\mathrm{CP})$ & - & 28,90 & 28,90 & 33,11 & 9,08 \\
\hline $\mathrm{EE}^{6}(E E)$ & - & 18,49 & 18,49 & 15,89 & 1,25 \\
\hline Cinzas $^{6}($ Ash $)$ & - & 5,00 & 5,00 & 4,55 & 7,23 \\
\hline $\mathrm{CT}^{6}(T C)$ & - & 47,61 & 47,61 & 46,45 & 82,44 \\
\hline $\mathrm{FDN}^{6}(N D F)$ & - & 17,40 & 17,40 & 11,54 & 67,70 \\
\hline $\mathrm{CNF}^{6}(N F C)$ & - & 30,21 & 30,21 & 34,91 & 14,74 \\
\hline
\end{tabular}

${ }^{1}$ Mistura mineral; ${ }^{2}$ Grão de soja moído; ${ }^{3}$ Grão de soja inteiro; ${ }^{4}$ Farelo de soja + milho moído; ${ }^{5}$ Simulação manual de pastejo $6 \%$ MS .

${ }_{1}^{1}$ Mineral mix; ${ }^{2}$ Ground whole soybean; ${ }^{3}$ Whole soybean; ${ }^{4}$ Soybean meal + ground corn; ${ }^{5}$ Hand plucking sample; $6 \%$ DM.

Tabela 3 - Peso vivo inicial (PVIJ - kg) e final (PVFJ - kg) dos animais em jejum, ganho de peso total (GPT- kg), ganho médio diário (GMD - kg/dia) e rendimento de carcaça fria (RCF- \%) nos diferentes tratamentos

Table 3 - Initial (IBW - $\mathrm{kg}$ ) and final (FBW - kg) body weights, total gain (TG - kg), average daily weight gain (ADWG - $\mathrm{kg} / \mathrm{day})$ and carcass yield (CY - \%) of different treatments

\begin{tabular}{|c|c|c|c|c|c|}
\hline \multirow[b]{3}{*}{ Item } & \multicolumn{4}{|c|}{ Tratamento } & \multirow[b]{3}{*}{ CV $(\%)$} \\
\hline & \multicolumn{4}{|c|}{ Treatment } & \\
\hline & $\mathrm{MM}^{1}(M M)$ & $\mathrm{GSM}^{2}(G W S)$ & $\operatorname{GSI}^{3}(W S B)$ & $\mathrm{FSM}^{4}(S M G C)$ & \\
\hline $\begin{array}{l}\text { PVIJ (ILW) } \\
\text { (IL) }\end{array}$ & 317,75 & 317,25 & 313,75 & 314,25 & - \\
\hline PVFJ (FLW) & 410,00 & 437,50 & 424,75 & 433,25 & - \\
\hline $\mathrm{GPT}^{5}(T G)$ & 92,25 & 120,25 & 111,00 & 119,00 & 20,71 \\
\hline $\mathrm{GMD}^{5}(A D G)$ & 0,870 & 1,013 & 1,005 & 1,012 & 20,71 \\
\hline $\mathrm{RCF}^{5}(\mathrm{CY})$ & 49,86 & 49,64 & 49,95 & 50,25 & 15,79 \\
\hline
\end{tabular}

${ }^{1}$ Mistura mineral; ${ }^{2}$ Grão de soja moído; ${ }^{3}$ Grão de soja inteiro; ${ }^{4}$ Farelo de soja + milho moído; ${ }^{5}$ Efeito relativo a tratamento não-significativo $(P>0,05)$ pelo teste SNK.

${ }^{1}$ Mineral mix; ${ }^{2}$ Ground whole soybean; ${ }^{3}$ Whole soybean; ${ }^{4}$ Soybean meal + ground corn; 5 Treatment effect not significant $(P>0.05)$ by SNK test.

Tabela 4 - Médias e coeficiente de variação (CV) obtidos para o pH e as concentrações de $\mathrm{N}-\mathrm{NH}_{3}(\mathrm{mg} / \mathrm{dL}$ de líquido ruminal) nos diferentes tratamentos

Table 4 - Means and coefficient of variation (CV) for $\mathrm{pH}$ and $\mathrm{N}-\mathrm{NH}_{3}$ concentration ( $\mathrm{mg} / \mathrm{dL}$ of ruminal fluid) of different treatments

\begin{tabular}{|c|c|c|c|c|c|}
\hline \multirow[b]{2}{*}{ Item } & \multicolumn{4}{|c|}{$\begin{array}{c}\text { Tratamento } \\
\text { Treatment }\end{array}$} & \multirow[b]{2}{*}{$\mathrm{CV}(\%)$} \\
\hline & $\mathrm{M}^{1}(M M)$ & $\mathrm{GSM}^{2}(G W S)$ & $\operatorname{GSI}^{3}(W S B)$ & $\mathrm{FSM}^{4}(S M G C)$ & \\
\hline $\mathrm{pH}$ & 6,58 & 6,37 & 6,55 & 6,53 & 3,25 \\
\hline $\mathrm{N}-\mathrm{NH}_{3}{ }^{5}$ & $8,77^{\mathrm{b}}$ & $13,48^{\mathrm{a}}$ & $13,31^{\mathrm{a}}$ & $13,94^{\mathrm{a}}$ & 9,62 \\
\hline
\end{tabular}

${ }^{1}$ Mistura mineral; ${ }^{2}$ Grão de soja moído; ${ }^{3}$ Grão de soja inteiro; ${ }^{4}$ Farelo de soja + milho moído.

Médias, na linha, seguidas por letras distintas, diferem $(P<0,05)$ pelo teste SNK.

${ }^{1}$ Mineral mix; ${ }^{2}$ Ground whole soybean; ${ }^{3}$ Whole soybean; ${ }^{4}$ Soybean meal + ground corn.

Means, within a row, followed by different letters differ $(P<0.05)$ by SNK test.

\section{Conclusões}

A suplementação com soja em diferentes formas físicas no período das águas em intervalos não-freqüentes proporciona ganhos médios adicionais em torno de $0,140 \mathrm{~kg} /$ dia em relação à suplementação com mistura mineral, promovendo redução do período de terminação de bovinos em pastejo.

O grão de soja inteiro pode ser utilizado como substituto ao farelo de soja na formulação de suplementos para bovinos em pastejo, sem prejudicar o desempenho produtivo e os parâmetros ruminais dos animais, podendo minimizar os custos com processamento.

\section{Literatura Citada}

ALBRO, J.D.; WEBER, D.W.; DELCURTO, T. Comparison of whole, raw soybeans, extruded soybeans, or soybean meal and barley on digestive characteristics and performance of weaned beef steers consuming mature grass hay. Journal of Animal Science, v.71, p.26-32, 1993. 
FALDET, M.A.; SATTER, L.D. Feeding heat-treated full fat soybeans to cows in early lactation. Journal of Dairy Science, v.74, p.3047-3054, 1991.

FARMER, C.G.; COCHRAN, R.C.; SIMMS, D.D. et al. The effects of several supplementation frequencies on forage use and the performance of beef cattle consuming dormant tallgrass prairie forage. Journal of Animal Science, v.79, p.2276-2285, 2001.

HOOVER, W.H. Chemical factors involved in ruminal fiber digestion. Journal of Dairy Science, v.69, n.10, p.27552766, 1986.

JOHNSON, A.D. Sample preparation and chemical analysis of vegetation. In: t'MANETJE, L.T. (Ed.) Measurement of grassland vegetation and animal production. Aberustwyth: Commonwealth Agricultural Bureaux. p.96-102, 1978.

LENG, R.A. Factors affecting the utilization of "poor-quality" forages by ruminants particularly under tropical conditions. Nutrition Research Review, v.3, n.3, p.277-303, 1990.

McMENIMAN, N.P. Methods of estimating intake of grazing animals. In: REUNIÃO ANUAL DA SOCIEDADE BRASILEIRA DE ZOOTECNIA, 34., 1997, Juiz de Fora. Anais... Juiz de fora: Sociedade Brasileira de Zootecnia, 1997. p.131-168.

MINSON, D.J. Forage in ruminant nutrition. New York: Academic Press, 1990. 483p.

MORAES, E.H.B.K.; PAULINO, M.F.; FIGUEIREDO, D.M. Suplementação infreqüente de novilhos de corte durante o período de transição águas/seca:desempenho. In: REUNIÃO ANUAL DA SOCIEDADE BRASILEIRA DE ZOOTECNIA, 42., 2005, Goiânia. Anais... Goiânia: Sociedade Brasileira de Zootecnia, 2005 (CD-ROM). Ambiência.

NATIONAL RESEARCH COUNCIL - NRC. Nutrient Requirements of dairy cattle. 7,ed. Washington, D.C. National Academy Press, 2001. 381p.

NOLAN, J.V.; LENG, R.A. Dynamic aspects of ammonia and urea metabolism in sheep. British Journal of Nutrition, v.27. p.177, 1972.

NOLAN, J.V.; NORTON, B.W.; LENG, R.A.. Further studies of the dynamics of nitrogen metabolism in sheep. British Journal of Nutrition, v.35, p.127, 1976

PAULINO, M.F.; DETMANN, E.; ZERVOUDAKIS, J.T. Suplementos múltiplos para recria e engorda de bovinos em pastejo. In: SIMPÓSIO DE PRODUÇÃO DE GADO DE CORTE, 2., 2001, Viçosa, MG. Anais... Viçosa, MG: SIMCORTE, 2001. p. 187-231.

PAULINO, M.F.; DETMANN, E.; VALADARES FILHO, S.C. Soja grão e caroço de algodão em suplementos múltiplos para terminação de bovinos mestiços em pastejo. Revista Brasileira de Zootecnia, v.31, n.1, p.484-491, 2002 (Suplemento).

PIRES, J.A.A.; CARNEIRO, J.M.; SILVESTRE, J.R. Cenário futuro do negócio agrícola de Minas Gerais. V-Cenário futuro para a cadeia produtiva de bovinos de corte em Minas Gerais. Belo Horizonte: Governo do Estado de Minas Gerais, 1995. 32p.
POPPI, D.P.; McLENNAN, S.R. Protein and energy utilization by ruminats at pasture. Journal of Animal Science, v.73, p.278290, 1995

SAMPAIO, A.A.M.; OLIVEIRA, M.S.; TOSI, H. et al. Utilização da soja grão e do farelo de soja na terminação de bovinos castrados e inteiros em confinamento. In: REUNIÃO ANUAL DA SOCIEDADE BRASILEIRA DE ZOOTECNIA, 37., 1995 , Brasília. Anais... Brasília: Sociedade Brasileira de Zootecnia, 1995. p.301-303.

SATTER, L.D.; SLYTER, L.L. Effect of ammonia concentration on rumen microbial protein in vitro. British Journal of Nutrition, v.32, n.2, p.199-208, 1974.

SILVA, D.J.; QUEIROZ, A.C. Análise de alimentos: métodos químicos e biológicos. 3.ed. Viçosa, MG: Universidade Federal de Viçosa, 2002. 235p.

SNIFFEN, C.J.; O'CONNOR, J.D.; Van SOEST, P.J. et al. A net carbohydrate and protein system for evaluating cattle diets: II. Carbohydrate and protein availability. Journal of Animal Science, v.70, n.11, p.3562-3577, 1992.

TICE, E.M.; EASTRIDGEM M.L.; FIRKINS, J.L. Raw soybeans and roasted soybeans of different particles sizes. 1. Digestibility and utilization by lactating cows. Journal of Dairy Science, v.76. p.224-235, 1993.

TEIXEIRA, J.C. Alimentação de bovinos leiteiros. Lavras: Universidade Federal de Lavras, Fundação de Apoio ao Ensino, Pesquisa e Extensão, 1997. 270p.

UNIVERSIDADE FEDERAL DE VIÇOSA - SAEG, UFV. Sistema de análises estatísticas e genéticas. Versão 8.1. Viçosa, $\mathrm{MG}$ : 2000. (Manual do usuário).

VALADARES FILHO, S.C.; ROCHA JR., V.R.; CAPELLE, E.R. Tabelas brasileiras de composição de alimentos para bovinos. Viçosa, MG: Universidade Federal de Viçosa, 2002. 297p.

Van SOEST, P.J.; ROBERTSON, J.B.; LEWIS, B.A. Methods for dietary fiber, and nonstarch polysaccharides in relation to animal nutrition. Journal of Dairy Science, v.74, n.10, p.3583-3597, 1991.

VIEIRA, P.F. Efeito do formaldeído na proteção de proteínas e lipídeos em rações de ruminantes. Viçosa, MG: Universidade Federal de Viçosa, 1980. 98p. Tese (Doutorado em Zootecnia) Universidade Federal de Viçosa, 1980. 